\title{
Evaluating the effects of sevelamer carbonate on cardiovascular structure and function in chronic renal impairment in Birmingham: the CRIB-PHOS randomised controlled trial
}

\author{
Colin D Chue ${ }^{1}$, Jonathan N Townend ${ }^{1}$, Richard P Steeds ${ }^{1}$, Charles J Ferro ${ }^{2^{*}}$
}

\begin{abstract}
Background: Serum phosphate is an independent predictor of cardiovascular morbidity and mortality in patients with chronic kidney disease and the general population. There is accumulating evidence that phosphate promotes arterial stiffening through structural vascular alterations such as medial calcification, which are already apparent in the early stages of chronic kidney disease.

Aim: To determine the effects of phosphate binding with sevelamer carbonate on left ventricular mass and function together with arterial stiffness in patients with stage 3 chronic kidney disease.

Methods/Design: A single-centre, prospective, randomised, double-blind, placebo-controlled trial of 120 subjects with stage 3 chronic kidney disease recruited from University Hospitals Birmingham NHS Foundation Trust. Baseline investigations include transthoracic echocardiography and cardiac magnetic resonance imaging to assess ventricular mass, volumes and function, applanation tonometry to determine pulse wave velocity and pulse wave analysis as surrogate measures of arterial stiffness and dual energy $x$-ray absorptiometry scanning to determine bone density. During an open-label run in phase, subjects will receive $1600 \mathrm{mg}$ sevelamer carbonate with meals for four weeks. They will then be randomised to either continue sevelamer carbonate or receive an identical placebo (60 subjects per arm) for the remaining 36 weeks. Four-weekly monitoring of serum electrolytes and bone biochemistry will be performed. All baseline investigations will be repeated at the end of the treatment period. The primary endpoint of the study is a reduction in left ventricular mass after 40 weeks of treatment. Secondary endpoints are: i) change in aortic compliance; ii) change in arterial stiffness; iii) change in arterial elastance; iv) change in left ventricular systolic and diastolic elastance; v) change in left ventricular function; and vi) change in bone density.

Trial Registration: This trial is registered at ClinicalTrials.gov: NCT00806481 and Current Controlled Trials: ISRCTN35254279.
\end{abstract}

\section{Background}

The risk of cardiovascular disease is elevated in patients with chronic kidney disease (CKD) with an inverse graded relationship to glomerular filtration rate (GFR) independent of other risk factors [1]. The magnitude of this excess risk varies according to age, but for patients

\footnotetext{
* Correspondence: charles.ferro@uhb.nhs.uk

${ }^{2}$ Department of Nephrology, Queen Elizabeth Hospital and University of Birmingham, Birmingham, UK

Full list of author information is available at the end of the article
}

with moderately impaired renal function at stage $3 \mathrm{~b}$ CKD (GFR 30-44 ml/min $/ 1.73 \mathrm{~m}^{2}$ ), cardiovascular risk is at least doubled [2]. Although cardiovascular risk in end stage kidney disease (ESKD) is elevated, the global burden of cardiovascular disease caused by early CKD is much greater in public health terms as approximately $10 \%$ of the general population have a GFR within the CKD stage 3 range $\left(30-59 \mathrm{ml} / \mathrm{min} / 1.73 \mathrm{~m}^{2}\right)$ [3]. These individuals are much more likely to die from cardiovascular disease than progress to ESKD [4].

\section{C) Biomed Central}


Atherosclerotic diseases such as myocardial infarction only account for a minority of cardiovascular deaths in patients with $C K D$, the remainder being attributable to congestive heart failure, sudden cardiac death and arrhythmia [5]. These appear to be driven by underlying structural abnormalities such as left ventricular hypertrophy, fibrosis and dysfunction, which are near universal in patients with CKD and are present even in the early stages of disease [6]. Recent work suggests that increased arterial stiffness plays a major role in the development of these myocardial abnormalities, and both increased left ventricular mass and increased arterial stiffness are of proven prognostic significance in CKD [7-10].

Serum phosphate is an independent predictor of cardiovascular morbidity and mortality in patients with CKD [11] and within the general population [12]. Reasons for this are unclear, but phosphate is intimately involved in the regulation of medial vascular smooth muscle growth and calcification giving rise to the possibility that it is acting as a mediator of increased arterial stiffness. Phosphate binders administered to control hyperphosphataemia in CKD might therefore be expected to reduce or slow the progression of arterial stiffness in addition to their primary role of preventing metabolic bone disease. The non-calcium-based phosphate binder sevelamer, which reduces hyperphosphataemia without increasing calcium-phosphate product, has near ideal pharmacological properties for such an action. Indeed, in three randomised controlled trials it has been shown to be superior to calcium-based phosphate binders in attenuating the progression of coronary artery and aortic calcification [13-15].

Although serum phosphate rises early in the course of CKD, phosphate binders are currently only used in latestage disease when major abnormalities of calcium and phosphate metabolism are present. By this time it is likely that arterial and ventricular function are already significantly impaired, partly through prolonged exposure of the vascular system to high levels of phosphate. This study aims to examine the effect of phosphate binding with sevelamer on left ventricular mass, markers of arterial stiffness and left ventricular function in early stage CKD.

\section{Methods \\ Hypothesis}

Phosphate binding with sevelamer carbonate will reduce left ventricular mass, improve indices of left ventricular systolic and diastolic function, and reduce arterial and cardiac stiffness in patients with stage 3 CKD.

\section{Study Design}

This is a single-centre prospective, randomised, doubleblind, placebo-controlled trial of 120 subjects with stage 3
CKD (defined as an estimated GFR 30-59 ml/min/1.73 $\mathrm{m}^{2}$ ) established on conventional treatment with an angiotensin converting enzyme inhibitor or angiotensin receptor blocker for at least 3 months before enrolment. GFR will be estimated by the 4-variable Modification of Diet in Renal Disease formula with serum creatinine recalibrated to be traceable to an isotope derived mass spectroscopy method [16]. Inclusion and exclusion criteria are detailed in Table 1.

\section{Baseline Studies}

All subjects will undergo a baseline visit (Figure 1) during which the following will be performed: i) questionnaire regarding past medical history, drug history and tobacco and alcohol consumption; ii) clinical examination of all systems; iii) measurement of height, weight, hips and waist; iv) 12-lead electrocardiogram (ECG); v) office brachial blood pressure and heart rate measurement in triplicate using the non-dominant arm following 15 minutes of rest with a validated oscillometric sphygmomanometer (HEM-705CP, Omron, Henfield, United Kingdom [17] or Dinamap Procare 200, GE Healthcare, United Kingdom [18]) according to British Hypertension Society guidelines [19]; vi) applanation tonometry to determine carotidfemoral aortic pulse wave velocity; vii) applanation tonometry to derive central pressure waveforms from pulse wave analysis and to determine central systolic and diastolic pressures and augmentation index; viii) dual energy $\mathrm{x}$-ray absorptiometry (DEXA) scanning to assess bone mineral density as recommended by the World Health Organisation [20,21]; ix) collection of serum and plasma following 30 minutes of supine rest for haematological and biochemical analysis including serum calcium,

\section{Table 1 Inclusion and exclusion criteria}

\begin{tabular}{l} 
Inclusion Criteria \\
\hline Age $18-80$ years \\
Chronic kidney disease stage 3 (estimated GFR $30-59 \mathrm{ml} / \mathrm{min} / 1.73 \mathrm{~m}^{2}$ ) \\
Office BP controlled to $<140 / 90 \mathrm{mmHg}$ for $\geq 12$ months before entry \\
Total cholesterol $<5.5 \mathrm{mmol} / \mathrm{L}$ \\
\hline Exclusion Criteria \\
Existing or previous treatment within the past year with a phosphate \\
binder or vitamin D analogue \\
Hyperphosphataemia (serum phosphate $>1.8 \mathrm{mmol} / \mathrm{L}$ ) \\
Hypophosphataemia (serum phosphate $<0.8 \mathrm{mmol} / \mathrm{L}$ ) \\
Uncontrolled secondary hyperparathyroidism (PTH $>80 \mathrm{pg} / \mathrm{ml}$ ) \\
Diabetes mellitus \\
Pregnancy \\
Women of child-bearing age not on contraception \\
Bowel obstruction \\
Dysphagia or other swallowing disorder \\
Severe gastrointestinal motility disorders including severe constipation \\
Previous major gastrointestinal tract surgery
\end{tabular}




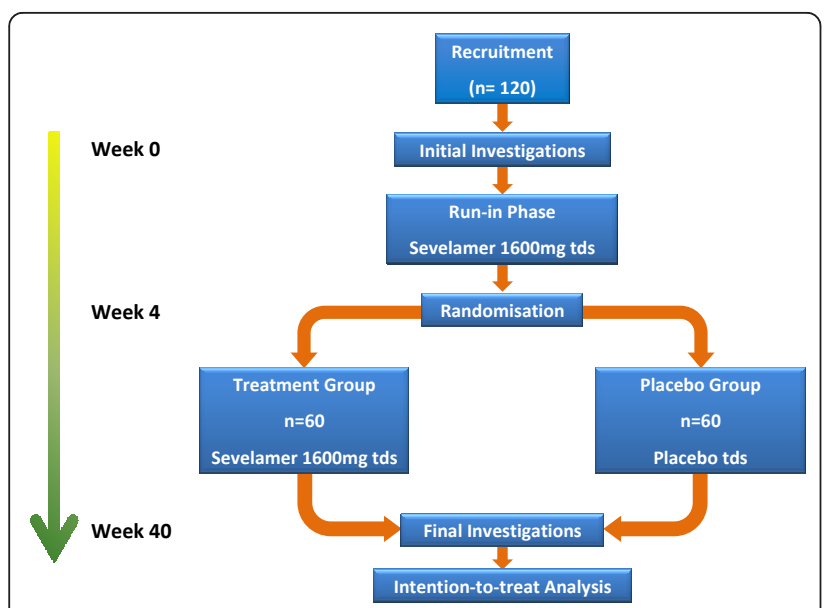

Figure 1 Study timeline. 120 subjects will undergo baseline investigations before entering a 4 week open-label run-in phase in which all subjects will receive $1600 \mathrm{mg}$ of sevelamer carbonate with meals. Participants will then be randomised to continue treatment with sevelamer carbonate $1600 \mathrm{mg}$ with meals or identical placebo for the remaining 36 weeks. Safety monitoring will be performed every four weeks. Investigations will be repeated at week 40 after which subjects will have completed participation in the study.

phosphate, 1,25-dihydroxyvitamin $\mathrm{D}$ and parathyroid hormone (PTH); $\mathrm{x}$ ) storage of serum and plasma at $-80^{\circ} \mathrm{C}$ for future assay of biomarkers associated with cardiovascular function and calcification; xi) collection of a spot urine sample to determine albumin: creatinine ratio; xii) storage of a spot urine sample at $-80^{\circ} \mathrm{C}$ for future proteomic studies; xiii) transthoracic echocardiography to determine systolic and diastolic ventricular function and measures of ventricular-vascular interaction; xiv) a lateral plain abdominal radiograph to semi-quantitatively assess abdominal aortic calcification as previously described [22]; xv) cardiac magnetic resonance imaging (CMR) to determine ventricular volumes, function and mass and aortic distensibility as previously described [23]; xvi) 24-hour urine collection for determination of phosphate excretion; and xvii) 24-hour ambulatory blood pressure and heart rate monitoring with a validated ambulatory blood pressure monitor (ABPM-04, Meditech, Budapest, Hungary) [24]. Eligible female subjects of childbearing age will undergo urine pregnancy testing prior to entry into the study.

\section{Cardiac Magnetic Resonance Imaging}

Cardiac magnetic resonance imaging will be performed using a 1.5-T scanner (Sonata Symphony, Siemens, Erlangen, Germany) with subjects in the supine position. Serial contiguous short axis cines will be piloted from the vertical long axis and horizontal long axis images of the left and right ventricles (ECG R wave-gated, steadystate free precession imaging [True-FISP]; temporal resolution $40-50 \mathrm{~ms}$, repetition time $3.2 \mathrm{~ms}$, echo time
$1.6 \mathrm{~ms}$, flip angle $60^{\circ}$, slice thickness $7 \mathrm{~mm}$ with $3 \mathrm{~mm}$ gap) in accordance with previously validated methodologies [23]. Analysis will be performed offline (Argus Software, Siemens, Erlangen, Germany) by a single blinded observer for the assessment of ventricular volumes (enddiastolic, end-systolic and stroke volumes), function (ejection fraction) and left ventricular mass [23,25]. Aortic distensibility will be assessed at the ascending aorta and proximal descending aorta at the level of the pulmonary artery and the distal descending aorta at the level of the diaphragm and calculated using previously validated formulae [26]. Brachial blood pressures will be simultaneously recorded at the time of scanning.

Dynamic tissue-tagging magnetic resonance imaging allows direct non-invasive assessment of regional systolic myocardial shortening and is a previously validated technique [27]. Spatial modulation of magnetization will be used to generate a uniform grid pattern with $8 \mathrm{~mm}$ tag separation on the left ventricular myocardium at three short axis sections (basal, equatorial and apex) and the horizontal long axis image using a fast field echo multishot sequence (temporal resolution $40-50 \mathrm{~ms}$, repetition time $3.9 \mathrm{~ms}$, echo time $4.4 \mathrm{~ms}$, voxel size $1.8 / 1.3 / 6.0$ $\mathrm{mm}^{3}$, flip angle $14^{\circ}$, tag grid angle $45^{\circ}$ with slice thickness $6 \mathrm{~mm}$ and a minimum number of 15 phases per cardiac cycle) with prospective ECG gating as previously described [28]. The myocardial grid will be followed through systole for deformation caused by ventricular contraction. Blinded analysis will be performed offline for left ventricular longitudinal shortening and apical and basal rotation as previously described [28].

\section{Pulse Wave Velocity and Pulse Wave Analysis}

Pulse wave velocity (SphygmoCor, AtCor Medical, Sydney) will be performed as previously described [29] following 15 minutes of supine rest using a high-fidelity micromanometer (SPC-301, Millar Instruments, Texas) to sequentially record ECG-gated carotid and femoral arterial waveforms. The path length will be calculated by subtracting the distance between the sternal notch and carotid recording site from the distance between the sternal notch and femoral site. This method is reproducible in both healthy subjects and patients with renal impairment $[30,31]$. Pulse wave analysis will be performed using the micromanometer to flatten, but not occlude, the radial artery using gentle pressure. Data will be collected directly into a portable computer and after 11 seconds of data capture, an averaged peripheral waveform and corresponding central waveform will be generated using a validated transfer function. The central waveform will be analysed using the system software to determine the augmentation index (AIx) and central aortic pulse and systolic pressures. AIx represents the difference between the second and first peaks of the 
central pressure waveform in systole, expressed as a percentage of the pulse pressure. Values will be reported as the mean of three stable readings. This method has been shown to be reproducible in both healthy subjects and in patients with renal impairment $[30,32]$. The results for AIx will be corrected to a heart rate of 75 beats/minute $\left(\mathrm{AIx}_{75}\right)$ [33]. All measurements will be made in triplicate and mean values used in analysis.

\section{Echocardiography}

A comprehensive transthoracic echocardiogram (Vivid 7, GE Vingmed Ultrasound, Horten, Norway) will be performed with the subject in the left lateral decubitus position by a single experienced echocardiographer using second harmonic imaging and an M3S multi-frequency transducer. All parameters will be measured in triplicate and averaged as per the recommendations of the American Society of Echocardiography [34]. Analysis will be performed offline by a single blinded observer using an EchoPAC workstation (GE Vingmed Ultrasound, Horten, Norway). Ventricular dimensions, wall thickness, chamber volumes and stroke volume will be determined using standard methods [35]. Left ventricular mass will be determined by the 2 -dimensional area-length formula and indexed to body surface area. Resting left ventricular diastolic function will be determined using standard techniques [36]. Peak systolic (s'), early diastolic (e') and late diastolic (a') mitral annular velocities will be measured at end expiration at the septal, lateral, inferior and anterior left ventricular walls with real time pulsed wave tissue Doppler [37].

Greyscale images for 2-dimensional left ventricular strain and strain rate imaging will be acquired in cineloop format in triplicate from the apical 4-, 2- and 3chamber views and parasternal short axis views at basal, equatorial and apical levels at end expiration at frame rates $>70 /$ second for offline analysis using commercially available software (Speqle Tracking, GE Healthcare, United Kingdom). The endocardial border will be manually tracked at end-systole and the software will then generate a region of interest that will be placed over the myocardium. This will enable frame-to-frame tracking of ultrasonic speckles that change position according to surrounding tissue motion throughout the cardiac cycle. Peak systolic velocities, strain, strain rate, rotation and twist will be measured for each myocardial segment in triplicate and averaged.

\section{Dual Energy X-ray Absorptiometry Scanning}

Dual energy $\mathrm{x}$-ray absorptiometry scanning (Hologic QDR Series 4500 with Discovery Software version 11.02:03, Hologic Europe, Zaventem, Belgium) will be used to assess bone mineral density of the lumbar spine (L1-L4) and both proximal femurs (femoral neck,
Ward's region, trochanteric region). Scans will be reported by an experienced bone densitometry clinical scientist blinded to clinical data.

\section{Run-in Phase}

Following baseline studies all subjects will receive $1600 \mathrm{mg}$ of sevelamer carbonate with meals for 4 weeks during an open-label run-in phase (Figure 1) to assess tolerability, efficacy, compliance and side effect profile. The development of new symptoms that may relate to treatment and compliance with medication will be assessed at 2-weekly intervals during run-in. Serum phosphate will also be measured at 2-weekly intervals. In the event that serum phosphate falls below $0.8 \mathrm{mmol} / \mathrm{L}$, the dose of sevelamer will be halved to $800 \mathrm{mg}$ with meals (Table 2) and levels rechecked to ensure serum phosphate is $>0.8 \mathrm{mmol} / \mathrm{L}$. If serum phosphate remains below this level after 6 weeks and/or a dose reduction subjects will be withdrawn from the study after a final set of measurements.

\section{Randomisation and Treatment Phase}

At the end of the open-label run-in phase subjects will attend for a second study visit and the following will be repeated: i) office brachial blood pressure and heart rate measurement in triplicate; ii) applanation tonometry to determine aortic pulse wave velocity; iii) applanation tonometry to derive central pressure waveforms from pulse wave analysis; iv) collection of serum and plasma for haematological and biochemical analysis; v) storage of serum and plasma at $-80^{\circ} \mathrm{C}$ for future assay of biomarkers associated with cardiovascular function and calcification; vi) collection of a spot urine sample to determine albumin: creatinine ratio; and vii) 24-hour urine collection for determination of phosphate excretion.

Participants will then be randomised by computer assignment to continue $1600 \mathrm{mg}$ (or half-dose) sevelamer with meals or receive an identical placebo for the remaining 36 weeks (Figure 1). During this blinded

Table 2 Management of serum phosphate levels during open-label run-in phase

\begin{tabular}{|c|c|c|}
\hline & $\begin{array}{l}\text { Serum Phosphate } \\
(\mathrm{mmol} / \mathrm{L})\end{array}$ & Action \\
\hline \multirow[t]{2}{*}{ Week 2} & $<0.8$ & $\begin{array}{l}\text { Reduce dose to } 800 \mathrm{mg} \text { tds and } \\
\text { continue to week } 4\end{array}$ \\
\hline & $>0.8$ & Continue to week 4 \\
\hline \multirow[t]{2}{*}{ Week 4} & $<0.8$ & $\begin{array}{l}\text { Reduce dose to } 800 \mathrm{mg} \text { tds and } \\
\text { continue to week } 6 \\
\text { If already on } 800 \mathrm{mg} \text { tds withdraw } \\
\text { from study after week } 4 \text { visit }\end{array}$ \\
\hline & $>0.8$ & Randomise \\
\hline \multirow[t]{2}{*}{ Week 6} & $<0.8$ & $\begin{array}{l}\text { Final measurements and withdraw } \\
\text { from study }\end{array}$ \\
\hline & $>0.8$ & Randomise \\
\hline
\end{tabular}


treatment phase subjects will undergo monitoring of renal function and serum calcium, phosphate and PTH every four weeks. Serum phosphate levels will be managed according to a pre-defined protocol during the treatment period (Table 3). All measurements performed at the initial main study visit (except for the plain lateral abdominal radiograph) will be repeated at a final visit 40 weeks after baseline studies, marking the end of subject participation in the study.

\section{Subject Withdrawal}

Withdrawal criteria are listed in Table 4. The average serum phosphate level of patients with stage 3 CKD enrolled in a previous study by the investigators was $1.2 \pm 0.2 \mathrm{mmol} / \mathrm{L}$ [38]. It is therefore felt unlikely that significant numbers of participants will need to be withdrawn because of hypophosphataemia. The majority of patients with stage 3 CKD do not require phosphatebinding medication for overt hyperphosphataemia and the prevention of metabolic bone disease. Should any subjects in the placebo group develop serum phosphate $>1.8 \mathrm{mmol} / \mathrm{L}$, they will be withdrawn from the study and rescue therapy with appropriate phosphate binders will be administered.

\section{Endpoints}

The primary end-point of the study will be a reduction in left ventricular mass after 40 weeks of treatment. Left ventricular mass is a powerful predictor of cardiovascular and all-cause mortality in the general population [39] and in CKD [40]. A therapeutic reduction in left ventricular mass has been shown to effectively reduce cardiovascular morbidity and mortality $[41,42]$. Secondary end points are: i) change in aortic compliance measured by CMR; ii) change in arterial stiffness as assessed using pulse wave velocity and pulse wave analysis; iii) change in arterial elastance measured by echocardiography; iv) change in left ventricular systolic and diastolic

Table 3 Management of serum phosphate levels during treatment phase

\begin{tabular}{lcl}
\hline & $\begin{array}{c}\text { Serum } \\
\text { Phosphate } \\
\text { ( } \mathbf{m m o l} / \mathbf{L})\end{array}$ & Action \\
\hline At visit & $<0.8$ & $\begin{array}{l}\text { Recheck serum phosphate within 1 } \\
\text { week } \\
\text { Continue routine 4-weekly checks }\end{array}$ \\
\hline $\begin{array}{l}\text { Within 1 week } \\
\text { of visit }\end{array}$ & $<0.8$ & $\begin{array}{l}\text { Reduce treatment/placebo dose to } \\
800 \text { mg tds and recheck in 2 } \\
\text { weeks } \\
\text { Continue routine 4-weekly checks }\end{array}$ \\
\hline 2 weeks after visit & $<0.8$ & $\begin{array}{l}\text { Final measurements and withdraw } \\
\text { from study } \\
\text { Continue routine 4-weekly checks }\end{array}$ \\
& $>0.8$ &
\end{tabular}

\section{Table 4 Withdrawal criteria}

\begin{tabular}{l} 
Withdrawal Criteria \\
\hline Pregnancy \\
Hypophosphataemia (serum $\mathrm{PO}_{4}<0.8 \mathrm{mmol} / \mathrm{L}$ despite dose reduction \\
of treatment/placebo) \\
Hyperphosphataemia (serum $\mathrm{PO}_{4}>1.8 \mathrm{mmol} / \mathrm{L}$ in subjects receiving \\
placebo) \\
Occurrence of any serious adverse event, intercurrent illness or \\
laboratory abnormality which, in the opinion of the investigators, \\
warrants the subject's permanent withdrawal from the study \\
Poor compliance with study medication \\
Poor attendance at study visits \\
Subject inability to tolerate study medication due to side effect profile \\
Subject decision to withdraw \\
Deteriorating renal function \\
Subject lost to follow-up (loss of contact before final study visit)
\end{tabular}

elastance measured by echocardiography; v) change in left ventricular function as assessed by tissue Doppler imaging, strain and strain rate analysis and measurement of torsion; and vi) change in bone density on DEXA scanning and/or magnetic resonance imaging.

\section{Planned Statistical Analysis}

Comparisons will be performed between the groups at baseline and after the 36 -week treatment phase. The normality of distribution of all continuous variables will be determined using a normality plot and the Kolmogorov-Smirnov test. Normally distributed variables will be analysed using unpaired t-tests, $\chi^{2}$ or repeated measures analysis of variance with corrections made for multiple comparisons. Variables not normally distributed will be log transformed prior to analysis to achieve normal distribution or, if this is not achieved, analysed by Mann-Whitney U or Kruskal-Wallis tests. Multiple linear regression models will be derived for left ventricular mass and measures of vascular and cardiac stiffness using stepwise regression analysis. Analysis will be by intention-to-treat. A p-value of $<0.05$ will be considered statistically significant.

Sample size calculations were based on the primary endpoint of change in left ventricular mass after 40 weeks of treatment. A previous study by our group evaluating the cardiovascular effects of spironolactone in patients with early CKD revealed a $14 \mathrm{~g}$ drop in left ventricular mass from baseline following 40 weeks of therapy [38]. Using data from this previous study, 55 subjects in each arm will provide at least $80 \%$ power of detecting an $8 \mathrm{~g}$ difference between the change in left ventricular mass from baseline to 40 weeks using a twotailed $\mathrm{t}$-test at the $5 \%$ significance level given a standard deviation of $15 \mathrm{~g}$ in the change in left ventricular mass from baseline. Recruiting 60 subjects to each group will allow a $10 \%$ withdrawal or dropout rate. 


\section{Monitoring and Safety Assessments}

All adverse events, including serious adverse events (SAEs), will be recorded and followed up for the duration of the study or until resolution. Assessment of adverse events will be performed by the study investigators. All SAEs will be graded and reported to the sponsor. Any suspected unexpected serious adverse reactions will be reported to the sponsor, ethics committee and Medicines and Healthcare products Regulatory Agency. This study has been reviewed and approved by West Midlands Research Ethics Committee. Written informed consent will be obtained from all study participants.

\section{Summary}

The demonstration of an important pathophysiological role for serum phosphate in the development of cardiovascular disease associated with CKD would be crucial in the understanding of this condition and have important implications for treatment. As left ventricular mass and arterial stiffness are prognostically significant markers in CKD, a positive effect would suggest that phosphate lowering in stage 3 CKD with the noncalcium-based phosphate binder sevelamer, in addition to conventional treatment for blood pressure and hypercholesterolaemia, is of prognostic value and would provide a rationale for a large clinical trial with cardiovascular morbidity and mortality as end-points.

\section{Abbreviations}

Aix: augmentation index; Alx $_{75}$ : augmentation index corrected to a heart rate of 75 beats/minute; CKD: chronic kidney disease; CMR: cardiac magnetic resonance; DEXA: dual energy x-ray absorptiometry; ECG: electrocardiogram; ESKD: end stage kidney disease; GFR: glomerular filtration rate; PTH: parathyroid hormone; SAEs: serious adverse events

\section{Acknowledgements}

We gratefully acknowledge the help of Dr Peter Nightingale, Statistician at the Wellcome Trust Clinical Research Facility, University Hospitals Birmingham NHS Foundation Trust, and Helen Jones and Theresa Brady, Research Nurses at the Wellcome Trust Clinical Research Facility, for their invaluable assistance. We would also like to thank Genzyme Corporation, Cambridge, Massachusetts for funding this trial and for providing the study drug and placebo.

\section{Author details}

'Department of Cardiology, Queen Elizabeth Hospital and University of Birmingham, Birmingham, UK. ²Department of Nephrology, Queen Elizabeth Hospital and University of Birmingham, Birmingham, UK.

\section{Authors' contributions \\ CJF, JNT, RPS and CDC all contributed to the design of the study, the drafting of the protocol and this manuscript. CDC will acquire the majority of the data. All authors will be involved in statistical analysis and data interpretation. All authors have read and approved the final version of the manuscript.}

\section{Competing interests}

The sponsor for this trial is University Hospitals Birmingham NHS Foundation Trust, Birmingham, UK. This investigator-led study is funded through an unrestricted educational grant from Genzyme Corporation, Cambridge, Massachusetts. Genzyme Corporation manufactures sevelamer carbonate
(Renvela ${ }^{{ }^{\circledR}}{ }$ ), a non-calcium-based phosphate binder currently licensed in Europe for the treatment of hyperphosphataemia in dialysis patients and CKD patients not on dialysis with serum phosphate $>1.78 \mathrm{mmol} / \mathrm{L}$, which has been provided free of charge for the purposes of this study. In addition CJF has received lecture and advisory board fees from Genzyme. No employee from Genzyme or any medical writers have been involved in the preparation of this manuscript.

Received: 21 June 2010 Accepted: 2 February 2011 Published: 2 February 2011

Go AS, Chertow GM, Fan D, McCulloch CE, Hsu CY: Chronic kidney disease and the risks of death, cardiovascular events, and hospitalization. N Engl J Med 2004, 351:1296-1305.

2. Foley RN, Parfrey PS, Sarnak MJ: Clinical epidemiology of cardiovascular disease in chronic renal disease. Am J Kidney Dis 1998, 32:S112-119.

3. Coresh J, Selvin E, Stevens LA, Manzi J, Kusek JW, Eggers P, Van Lente F, Levey AS: Prevalence of chronic kidney disease in the United States. JAMA 2007, 298:2038-2047.

4. Foley RN, Murray AM, Li S, Herzog CA, McBean AM, Eggers PW, Collins AJ: Chronic kidney disease and the risk for cardiovascular disease, renal replacement, and death in the United States Medicare population, 1998 to 1999. J Am Soc Nephrol 2005, 16:489-495.

5. USRDS 2006 Annual Data Report. US Renal Data System Bethesda, MD National Institutes of Health, National Institute of Diabetes and Digestive and Kidney Diseases; 2006.

6. Edwards NC, Ferro CJ, Townend JN, Steeds RP: Aortic distensibility and arterial-ventricular coupling in early chronic kidney disease: a pattern resembling heart failure with preserved ejection fraction. Heart 2008, 94:1038-1043.

7. Pannier B, Guerin AP, Marchais SJ, Safar ME, London GM: Stiffness of capacitive and conduit arteries: prognostic significance for end-stage renal disease patients. Hypertension 2005, 45:592-596.

8. Blacher J, Guerin AP, Pannier B, Marchais SJ, Safar ME, London GM: Impact of aortic stiffness on survival in end-stage renal disease. Circulation 1999, 99:2434-2439.

9. Tucker B, Fabbian F, Giles M, Thuraisingham RC, Raine AE, Baker LR: Left ventricular hypertrophy and ambulatory blood pressure monitoring in chronic renal failure. Nephrol Dial Transplant 1997, 12:724-728.

10. Parfrey PS, Foley RN, Harnett JD, Kent GM, Murray DC, Barre PE: Outcome and risk factors for left ventricular disorders in chronic uraemia. Nephrol Dial Transplant 1996, 11:1277-1285.

11. Kestenbaum B, Sampson JN, Rudser KD, Patterson DJ, Seliger SL, Young B, Sherrard DJ, Andress DL: Serum phosphate levels and mortality risk among people with chronic kidney disease. J Am Soc Nephrol 2005, 16:520-528.

12. Tonelli M, Sacks F, Pfeffer M, Gao Z, Curhan G: Relation between serum phosphate level and cardiovascular event rate in people with coronary disease. Circulation 2005, 112:2627-2633.

13. Chertow GM, Burke SK, Raggi P: Sevelamer attenuates the progression of coronary and aortic calcification in hemodialysis patients. Kidney Int 2002, 62:245-252.

14. Russo D, Miranda I, Ruocco C, Battaglia Y, Buonanno E, Manzi S, Russo L, Scafarto A, Andreucci VE: The progression of coronary artery calcification in predialysis patients on calcium carbonate or sevelamer. Kidney Int 2007, 72:1255-1261.

15. Block GA, Spiegel DM, Ehrlich J, Mehta R, Lindbergh J, Dreisbach A, Raggi P: Effects of sevelamer and calcium on coronary artery calcification in patients new to hemodialysis. Kidney Int 2005, 68:1815-1824.

16. Levey AS, Bosch JP, Lewis JB, Greene T, Rogers N, Roth D: A more accurate method to estimate glomerular filtration rate from serum creatinine: a new prediction equation. Modification of Diet in Renal Disease Study Group. Ann Intern Med 1999, 130:461-470.

17. O'Brien E, Mee F, Atkins N, Thomas M: Evaluation of three devices for selfmeasurement of blood pressure according to the revised British Hypertension Society Protocol: the Omron HEM-705CP, Philips HP5332, and Nissei DS-175. Blood Press Monit 1996, 1:55-61.

18. Reinders A, Reggiori F, Shennan AH: Validation of the DINAMAP ProCare blood pressure device according to the international protocol in an adult population. Blood Press Monit 2006, 11:293-296.

19. Williams B, Poulter NR, Brown MJ, Davis M, Mclnnes GT, Potter JF, Sever PS, Mc GTS: Guidelines for management of hypertension: report of the 
fourth working party of the British Hypertension Society, 2004-BHS IV. J Hum Hypertens 2004, 18:139-185.

20. Assessment of fracture risk and its application to screening for postmenopausal osteoporosis. Technical Report Series, No 843 Geneva, Switzerland: World Health Organisation; 1994.

21. Miller PD, Zapalowski C, Kulak CA, et al: Bone densitometry: the best way to detect osteoporosis and to monitor therapy. J Clin Endocrinol Metab 1999, 84:867-871.

22. Bellasi A, Ferramosca E, Muntner P, Ratti C, Wildman RP, Block GA, Raggi P: Correlation of simple imaging tests and coronary artery calcium measured by computed tomography in hemodialysis patients. Kidney Int 2006, 70:1623-1628.

23. Maceira AM, Prasad SK, Khan M, Pennell DJ: Normalized left ventricular systolic and diastolic function by steady state free precession cardiovascular magnetic resonance. J Cardiovasc Magn Reson 2006, 8:417-426.

24. Barna I, Keszei A, Dunai A: Evaluation of Meditech ABPM-04 ambulatory blood pressure measuring device according to the British Hypertension Society protocol. Blood Press Monit 1998, 3:363-368.

25. Myerson SG, Bellenger NG, Pennell DJ: Assessment of left ventricular mass by cardiovascular magnetic resonance. Hypertension 2002, 39:750-755.

26. Groenink M, de Roos A, Mulder BJ, Spaan JA, van der Wall EE: Changes in aortic distensibility and pulse wave velocity assessed with magnetic resonance imaging following beta-blocker therapy in the Marfan syndrome. Am J Cardiol 1998, 82:203-208.

27. Yeon SB, Reichek N, Tallant BA, Lima JA, Calhoun LP, Clark NR, Hoffman EA, Ho KK, Axel L: Validation of in vivo myocardial strain measurement by magnetic resonance tagging with sonomicrometry. J Am Coll Cardiol 2001, 38:555-561.

28. Young AA, Imai H, Chang CN, Axel L: Two-dimensional left ventricular deformation during systole using magnetic resonance imaging with spatial modulation of magnetization. Circulation 1994, 89:740-752.

29. Laurent S, Cockcroft J, Van Bortel L, Boutouyrie P, Giannattasio C, Hayoz D, Pannier B, Vlachopoulos C, Wilkinson I, Struijker-Boudier H: Expert consensus document on arterial stiffness: methodological issues and clinical applications. Eur Heart J 2006, 27:2588-2605.

30. Wilkinson IB, Fuchs SA, Jansen IM, Spratt JC, Murray GD, Cockcroft JR, Webb DJ: Reproducibility of pulse wave velocity and augmentation index measured by pulse wave analysis. J Hypertens 1998, 16:2079-2084.

31. Wimmer NJ, Townsend RR, Joffe MM, Lash JP, Go AS: Correlation between pulse wave velocity and other measures of arterial stiffness in chronic kidney disease. Clin Nephrol 2007, 68:133-143.

32. Savage MT, Ferro CJ, Pinder SJ, Tomson CR: Reproducibility of derived central arterial waveforms in patients with chronic renal failure. Clin Sci (Lond) 2002, 103:59-65.

33. Wilkinson IB, MacCallum H, Flint L, Cockcroft JR, Newby DE, Webb DJ: The influence of heart rate on augmentation index and central arterial pressure in humans. J Physiol 2000, 525(Pt 1):263-270.

34. Schiller NB, Shah PM, Crawford M, DeMaria A, Devereux R, Feigenbaum H, Gutgesell H, Reichek N, Sahn D, Schnittger I, et al: Recommendations for quantitation of the left ventricle by two-dimensional echocardiography. American Society of Echocardiography Committee on Standards, Subcommittee on Quantitation of Two-Dimensional Echocardiograms. J Am Soc Echocardiogr 1989, 2:358-367.

35. Lang RM, Bierig M, Devereux RB, Flachskampf FA, Foster E, Pellikka PA, Picard MH, Roman MJ, Seward J, Shanewise JS, et al: Recommendations for chamber quantification: a report from the American Society of Echocardiography's Guidelines and Standards Committee and the Chamber Quantification Writing Group, developed in conjunction with the European Association of Echocardiography, a branch of the European Society of Cardiology. J Am Soc Echocardiogr 2005, 18:1440-1463.

36. Nagueh SF, Appleton CP, Gillebert TC, Marino PN, Oh JK, Smiseth OA, Waggoner AD, Flachskampf FA, Pellikka PA, Evangelista A: Recommendations for the evaluation of left ventricular diastolic function by echocardiography. J Am Soc Echocardiogr 2009, 22:107-133.

37. Alam M, Wardell J, Andersson E, Samad BA, Nordlander R: Characteristics of mitral and tricuspid annular velocities determined by pulsed wave Doppler tissue imaging in healthy subjects. J Am Soc Echocardiogr 1999, 12:618-628.
38. Edwards NC, Steeds RP, Stewart PM, Ferro CJ, Townend JN: Effect of spironolactone on left ventricular mass and aortic stiffness in early-stage chronic kidney disease: a randomized controlled trial. J Am Coll Cardiol 2009, 54:505-512.

39. Levy D, Garrison RJ, Savage DD, Kannel WB, Castelli WP: Prognostic implications of echocardiographically determined left ventricular mass in the Framingham Heart Study. N Engl J Med 1990, 322:1561-1566.

40. Silberberg JS, Barre PE, Prichard SS, Sniderman AD: Impact of left ventricular hypertrophy on survival in end-stage renal disease. Kidney Int 1989, 36:286-290.

41. Devereux RB, Wachtell K, Gerdts E, Boman K, Nieminen MS, Papademetriou V, Rokkedal J, Harris K, Aurup P, Dahlof B: Prognostic significance of left ventricular mass change during treatment of hypertension. JAMA 2004, 292:2350-2356.

42. Wachtell $K$, Okin PM, Olsen MH, Dahlof B, Devereux RB, Ibsen H, Kjeldsen SE, Lindholm LH, Nieminen MS, Thygesen K: Regression of electrocardiographic left ventricular hypertrophy during antihypertensive therapy and reduction in sudden cardiac death: the LIFE Study. Circulation 2007, 116:700-705.

doi:10.1186/1745-6215-12-30

Cite this article as: Chue et al: Evaluating the effects of sevelamer carbonate on cardiovascular structure and function in chronic renal impairment in Birmingham: the CRIB-PHOS randomised controlled trial. Trials 2011 12:30.

\section{Submit your next manuscript to BioMed Central and take full advantage of:}

- Convenient online submission

- Thorough peer review

- No space constraints or color figure charges

- Immediate publication on acceptance

- Inclusion in PubMed, CAS, Scopus and Google Scholar

- Research which is freely available for redistribution 